Vol 11, Issue 11, 2018

\title{
ISOLATION AND CHARACTERIZATION OF $\beta$-SITOSTEROL FROM ELAEAGNUS ANGUSTIFOLIA CULTIVATED IN IRAQ
}

\author{
RAND A AZEEZ*, IBRAHIM S ABAAS, ENAS J KADHIM \\ Department of Pharmacognosy and Medicinal Plants, College of Pharmacy, Al Yarmouk University College, Baghdad, Iraq. \\ Email: Randalgebory6@gmail.com
}

Received: 10 August 2018, Revised and Accepted: 14 September 2018

\section{ABSTRACT}

Objective: The aim of our study was to investigate chemical constituents of leaves and seeds of Elaeagnus angustifolia since no phytochemical investigation had been done previously in Iraq.

Methods: Phytochemical screening of the extracts obtained from the leaves of E. angustifolia indicated the presence of flavonoids (type of flavonols), saponins, alkaloids, steroids, and terpenoids. Thin-layer chromatography fingerprinting and the spraying reagent (concentrated $\mathrm{H}_{2} \mathrm{SO}_{4}$ and vanillin in ethanol) were used to identify the hexane extract containing phytosterols.

Results: The different chromatographic and spectroscopic results revealed the presence of $\beta$-sitosterol isolated from E. angustifolia.

Conclusion: The isolation and purification afforded white crystalline powder which was subjected to chemical and spectral identification by infrared and ${ }^{1} \mathrm{H}$-nuclear magnetic resonance. The compound was identified as $\beta$-sitosterol.

Keywords: Elaeagnus angustifolia, $\beta$-Sitosterol, ${ }^{1} \mathrm{H}$ nuclear magnetic resonance.

(C) 2018 The Authors. Published by Innovare Academic Sciences Pvt Ltd. This is an open access article under the CC BY license (http://creativecommons. org/licenses/by/4. 0/) DOI: http://dx.doi.org/10.22159/ajpcr.2018.v11i11.29030

\section{INTRODUCTION}

Medicinal plants are very ancient and true natural medicines which are useful for the treatment of different diseases. They can be used directly or in extracted forms for the management of various ailments due to the presence of various secondary metabolites [1].

Elaeagnus angustifolia is a member of Elaeagnaceae family. This family includes three genera and about 50 species [2]. It is a perennial [3] deciduous shrub or large tree with a height of up to $7 \mathrm{~m}$, leaves are alternate, lanceolate, and covering of silvery scale. Flowers introduce in cluster with creamy yellow color. Fruits are small, long, orange-red and covered in silvery scale. This plant has a capacity to grow under a wide range of environmental conditions [4]. Plants belonging to this genus are famous for its medical benefits. Recent pharmacological studies have shown that E. angustifolia L. has anti-inflammatory, antimicrobial, antioxidant, antitumor, and cardiovascular effect [5]. A large number of phytochemical components have been derived from Russian olive and made this plant a source of flavonoids, alkaloids, saponin ,terpens and complicated sterols and sterols [6] as shown in Fig. 1.

$\beta$-sitosterol belongs to the group of phytosterols, which particularly includes stigmasterol and campesterol. Phytosterols are crucial steroid molecules that stabilize the phospholipid bilayers of cellular membranes in plants, having similar structural and biological functions to cholesterol, and are a major group of bioactive constituents with well-proven bioactivity. Phytosterols show a variety of health benefits in vivo, in particular, protection against various chronic ailments, such as cardiovascular diseases, diabetes, cancer, and hepatic injury. It is worth mentioning that phytosterols have been attracting much interest because of their well-known cholesterol-lowering property recently [7]. The main objective of this study is to investigate and isolate this compound from E. angustifolia cultivated in Iraq since it is an important compound in therapy.

\section{MATERIALS AND METHODS}

\section{Plant material}

E. angustifolia leaves were collected from Al-Musayyib area, Babil Province, Iraq, during March and dried in shade at room temperature and grinded as powder and weighed. The plant was identified and authenticated by Prof. Dr. Ibrahim Saleh Abaas/Head of the Department of the College of Pharmacy, University of Al-Mustansiriyah.

\section{Extraction of terpene}

Shade-dried pulverized plant material $(100 \mathrm{~g})$ from plant leaves was extracted by Soxhlet apparatus with hexane $(700 \mathrm{ml})$, the extract was filtered, and the solvent was evaporated under reduced pressure using rotary evaporator. Hexane extract was analyzed for the presence of terpene using thin-layer chromatography (TLC) with spray reagent and confirmed by gas chromatography-mass spectrometry (GC-MS) and liquid chromatography (LC)-MS analysis.

\section{Isolation of sitosterol by preparative TLC}

Preparation of stationary phase

Readymade silica gel GF 254 plates with a layer thickness of $0.25 \mathrm{~mm}$, dimension $20 \mathrm{~cm} \times 20 \mathrm{~cm}$. The plates were reactivated by heating in the oven at $100^{\circ} \mathrm{C}$ for $15 \mathrm{~min}$, left to cool, and used for application after allocation of the baseline and the solvent front.

\section{Prepration of solvent system}

Mobile phase for sterols (chloroform:acetone) was mixed in a conical flask and introduced in the jar. The jar was lined with a filter paper, closed tightly, and left for saturation.

\section{Application of sample}

About $2 \mathrm{~g}$ of the sample was dissolved in absolute methanol and applied on the baseline of TLC plates. 


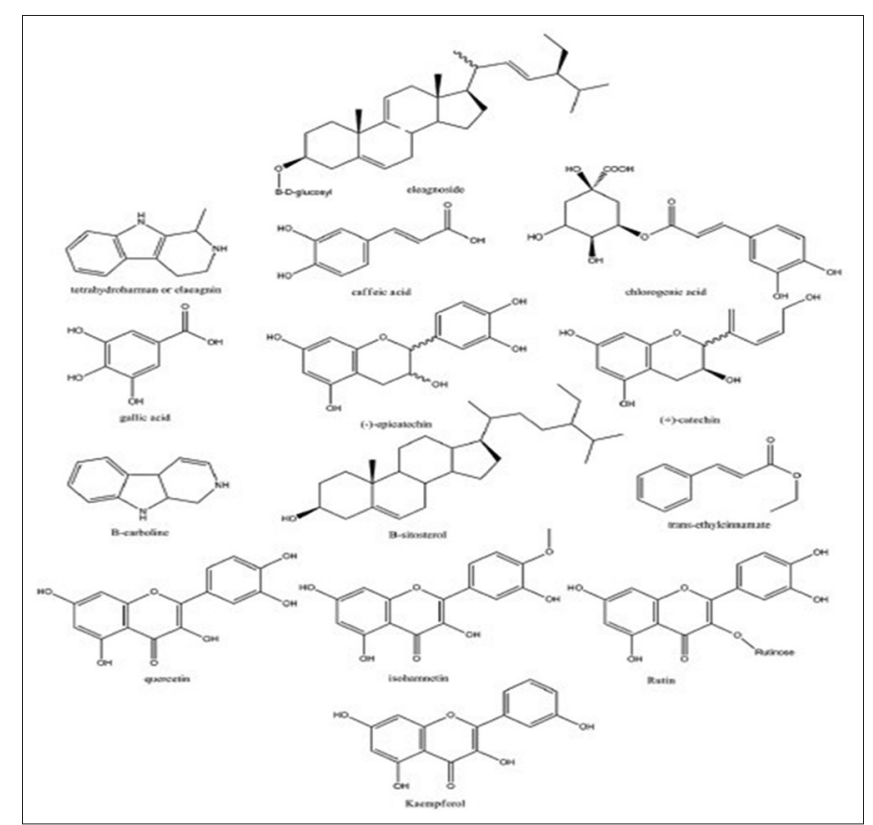

Fig. 1: Important components of Elaeagnus angustifolia $\beta$-sitosterol $\left[\mathrm{C}_{29} \mathrm{H}_{50} \mathrm{O}\right]$

\section{Detection of separated spot}

Detection was done by spraying side of plate with vanillin-sulfuric acid reagent. The purity of each band was checked by analytical TLC until single spot on TLC plate is obtained for identification with a reference standard.

\section{Method of identification of chemicals}

GC-MS

GC-MS was carried out to detect the presence of terpenes in the plant extract. GC-MS conditions for detection of terpenes were: the carrier gas was helium, the injection volume was $1 \mu \mathrm{L}$, and the split ratio was 2.0. Injection temperature: $250^{\circ} \mathrm{C}$. Column temperatures: From $80^{\circ} \mathrm{C}$ and rose up to $310^{\circ} \mathrm{C}$ at a rate of $10^{\circ} \mathrm{C} / \mathrm{min}$.

\section{LC/MS analysis}

LC/MS analysis of phytosterols in the hexane extract, a SHIMADZU LAB solutions using beta-sitosterol as standard, C18 column (2.1 $\mathrm{mm} \times 50 \mathrm{~mm}, 5 \mu \mathrm{m})$. An isocratic mobile phase of acetonitrile/ methanol $(99: 1, \mathrm{v} / \mathrm{v})$ was used at a flow rate of $600 \mu \mathrm{L} / \mathrm{min}$, and the injection volume was $10 \mu \mathrm{L}$. Stock solutions of standard compound were prepared by dissolving compound at $1.000 \mathrm{mg} / \mathrm{mL}$ in isopropanol.

\section{Structure elucidation of $\beta$-sitosterol}

- Fourier transform infrared (FTIR): FTIR spectroscopy is a technique for material analysis; it offers quantitative and qualitative analysis of the sample. FTIR identified chemical bands in molecules, the range of scanning $4000-400 \mathrm{~cm}^{-1}$. IR radiation is passed through a sample. Some of the IR radiation is absorbed by the sample, and some is transmitted. The resulting spectrum represents the molecular absorption and transmission, creating a molecular fingerprint of the sample. IR spectra was done using Nicolet NEXUS 670 FT-IR.

- ${ }^{1} \mathrm{H}$-nuclear magnetic resonance (NMR): The ${ }^{1} \mathrm{H}-\mathrm{NMR}$ spectra were performed at the University of Jordan, Faculty of Science, and Department of Chemistry. Instrument Model: Bruker $500 \mathrm{MHz}$-Avance III. Chemical shift is in part per million (ppm) with reference to the chemical shift of the deuterated solvent or the internal standard tetramethylsilane.

\section{RESULTS AND DISCUSSIONS}

Natural products have always been a preferred choice of all as it plays a great role in discovering new medicines. During extraction, solvents

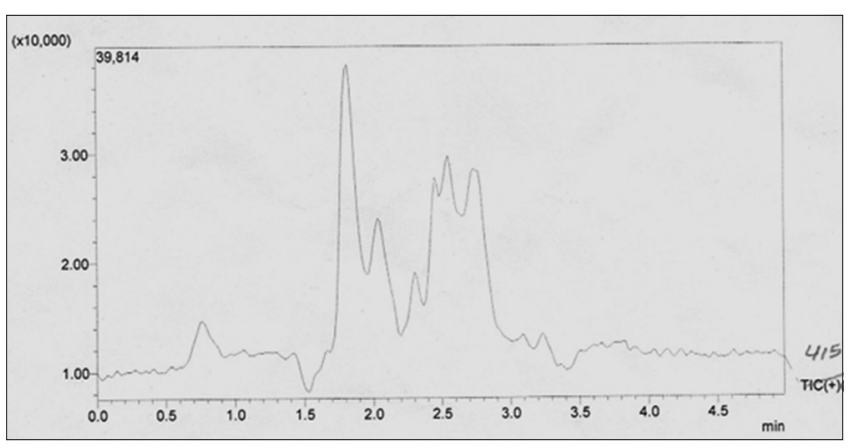

Fig. 2: Chromatogram of $\beta$-sitosterol

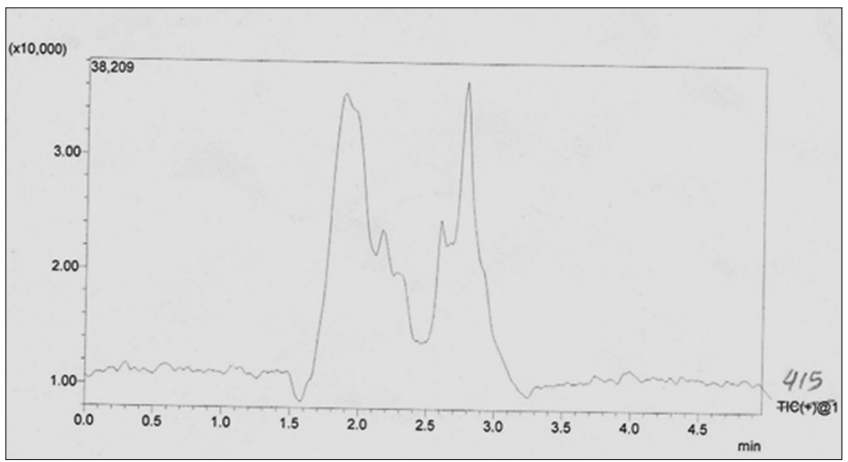

Fig. 3: Chromatogram of unknown

Table 1: $\mathbf{R}_{\mathrm{f}}$ value of standard and extract

\begin{tabular}{ll}
\hline Solvent system & Chloroform:Acetone \\
\hline $\mathrm{R}_{\mathrm{f}}$ value of $\beta$-sitosterol standard & 0.280 \\
$\mathrm{R}_{\mathrm{f}}$ value of $\beta$-sitosterol in extract & 0.260 \\
\hline
\end{tabular}

diffuse into the solid plant material and solubilize compounds with similar polarity [8] 
Table 2: Characteristic FT-IR Absorption of $\beta$-sitosterol

\begin{tabular}{lll}
\hline Compound & Bands $\left(\mathbf{c m}^{-1}\right)$ & Interpretation \\
\hline & $3399.85-3328.28$ & Stretching vibration of OH \\
Stretching vibration of CH alkane (symmetric and asymmetric) \\
Streching vibration of $\mathrm{CH}$ alkene
\end{tabular}

FT-IR: Fourier transform infrared

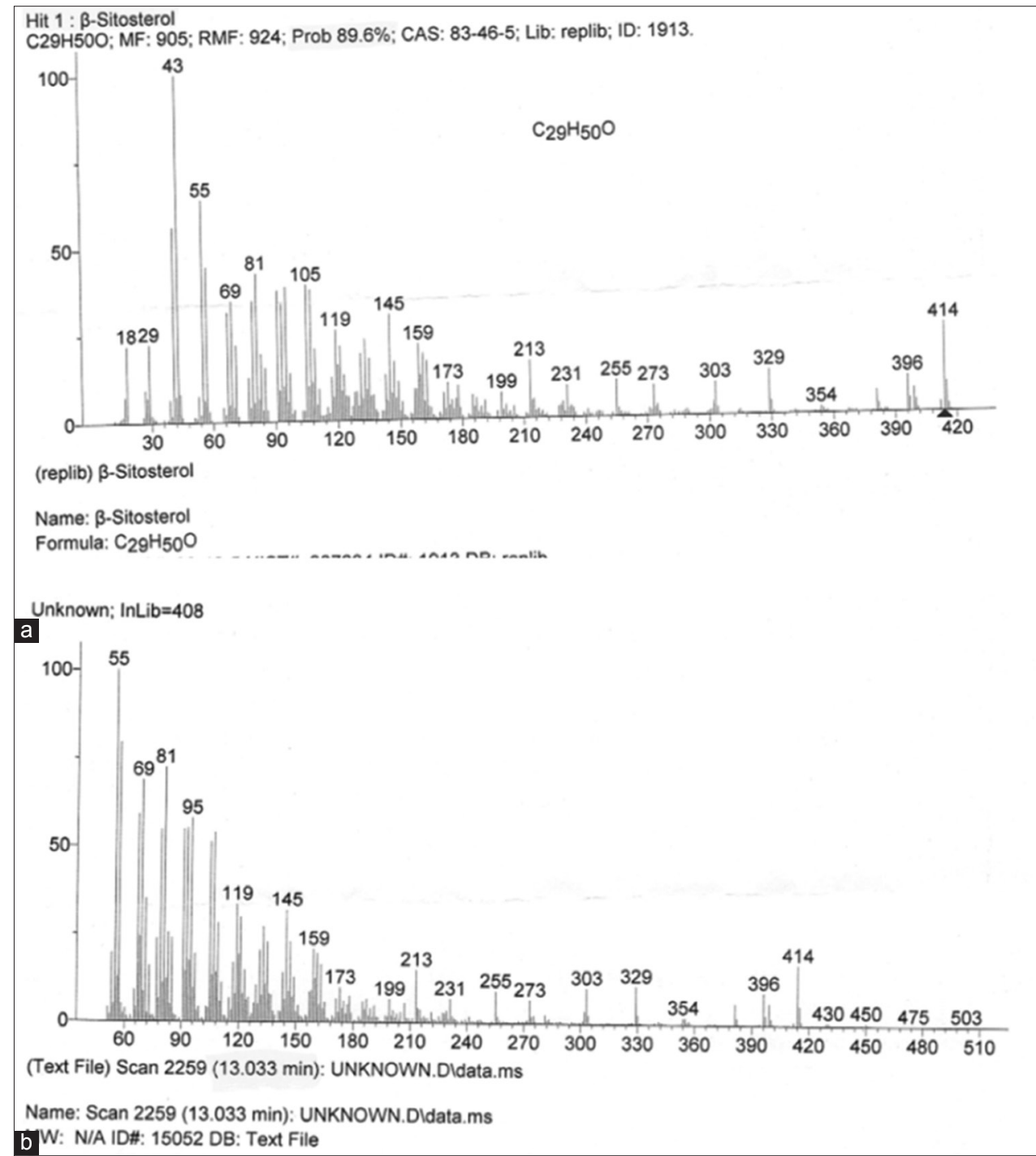

Fig. 4: ( $a$ and b) Gas chromatography-mass spectrometry chromatogram of $\beta$-sitosterol

Hexane extract of the plant was investigated by TLC which revealed the presence of $\beta$-sitosterol that appeared as spot in mobile phase (chloroform:acetone) against $\beta$-sitosterol reference standard, and the spot of extract appeared the same $\mathrm{R}_{\mathrm{f}}$ value as that in reference standard on TLC plate as shown in Table 1 , as indicated by the development of violet spots after spraying by vanillin sulfuric acid spray reagent [9].

\section{LC-MS analysis}

The chromatogram shows intensity of ions in mass spectrum that proportional to the compound in the sample ( $\beta$-sitosterol) in database (Figs. 2 and 3).

\section{GC/MS analysis}

The chromatogram showed peak with retention time (13.033 min) corresponding to the molecular ion peak at $414 \mathrm{~m} / \mathrm{e}$ in comparison with NIST83-46-5 database (Fig. 4).

\section{Fragmentation pattern of $\boldsymbol{\beta}$-sitosterol}

$\beta$-sitosterol molecular ion observed at $\mathrm{m} / \mathrm{z} 414$ that corresponds to the molecular formula C29H500. Peak at m/z 396 resulted from loss of water molecule from the molecular ion which will further dealkylated to yield peak at $\mathrm{m} / \mathrm{z} 381$.

Peakatm/z273 is for fragmentation of C17-C20 cleavage. The dehydration of $\mathrm{m} / \mathrm{z} 273$ fragment will yield m/z 255 as shown in Fig. 5 [10]. 


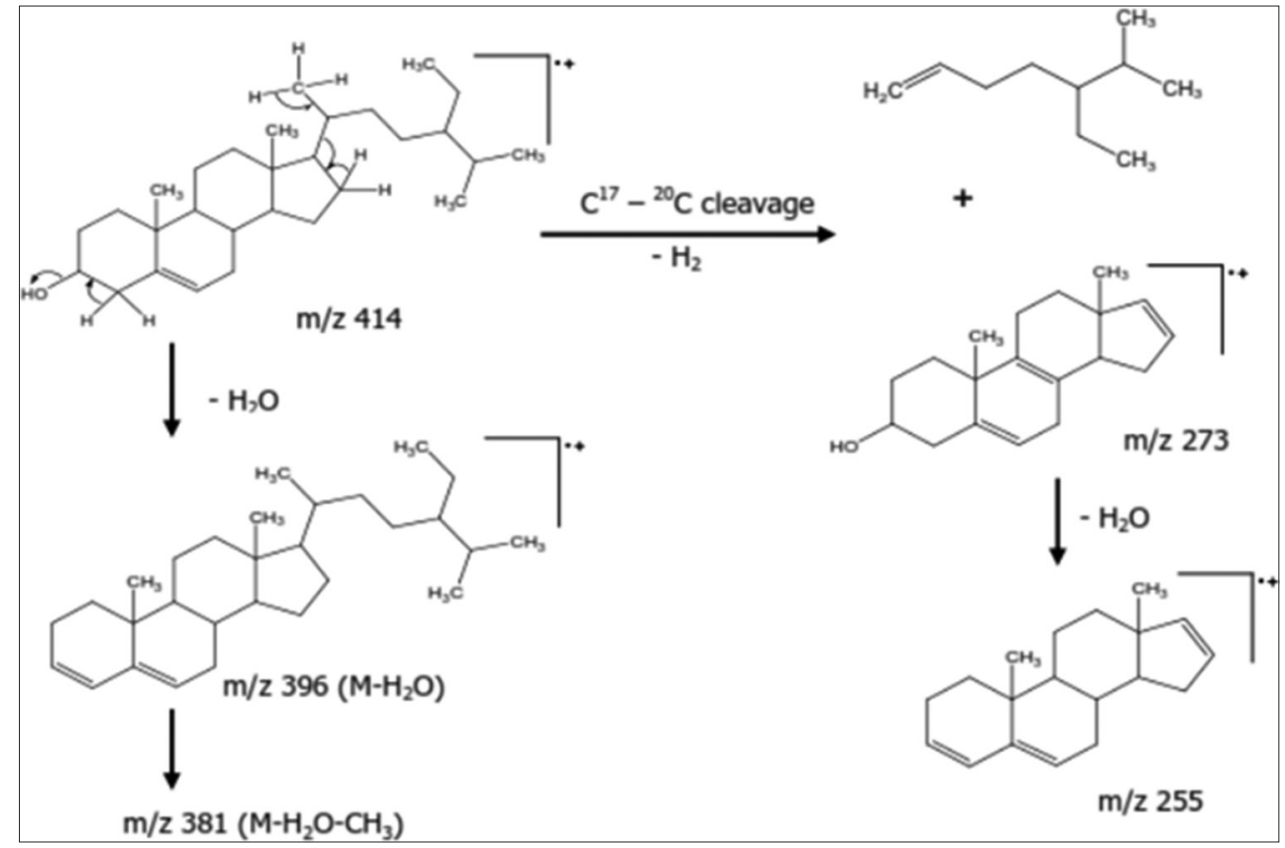

Fig. 5: Fragmentation pattern of $\beta$-sitosterol

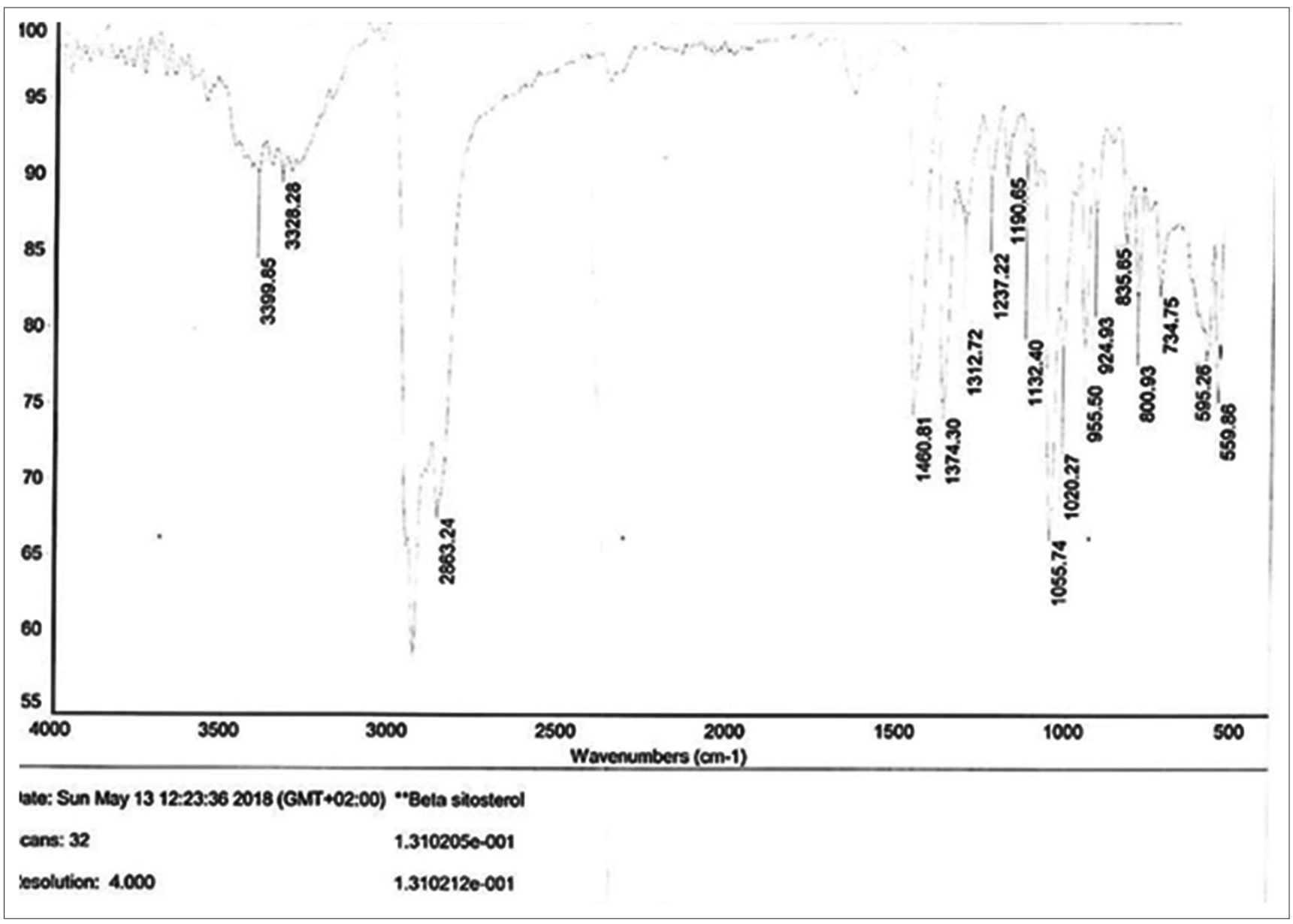

Fig. 6: The Fourier transform infrared spectra of the $\beta$-sitosterol 
Table 3: ${ }^{1} \mathrm{H}-\mathrm{NMR}$ chemical shift values for compound recorded in $\mathrm{CDCl} 3$ (500 MHz)

\begin{tabular}{|c|c|c|c|}
\hline $\begin{array}{l}\text { Carbon } \\
\text { atom }\end{array}$ & $\begin{array}{l}\text { Chemical shift } \\
\text { (ppm) }\end{array}$ & No. of $\mathbf{H}$ & Interpretation \\
\hline $\mathrm{C} 1$ & $1.3151,1.0585$ & & \\
\hline $\mathrm{C} 2$ & $1.52,1.2793$ & & \\
\hline $\mathrm{C} 3$ & 3.5283 & $1 \mathrm{H}$ & Singlet, alcoholic proton \\
\hline $\mathrm{C} 4$ & $2.2143,1.965$ & & \\
\hline C6 & 5.3392 & $1 \mathrm{H}$ & Triplet, $\mathrm{C}=\mathrm{CH} 2$ \\
\hline $\mathrm{C} 7$ & $2.2878,1.0765$ & & \\
\hline $\mathrm{C} 8$ & 1.037 & & \\
\hline C9 & 1.1712 & & \\
\hline C11 & $1.6285,1.3828$ & & \\
\hline C12 & 1.5117 & & \\
\hline C14 & 1.0497 & & \\
\hline C15 & $1.9808,1.6518$ & & \\
\hline C16 & $1.9419,1.6518$ & & \\
\hline C17 & 1.1192 & & \\
\hline C18 & 1.0366 & $3 \mathrm{H}$ & Methyl group \\
\hline C19 & 1.2019 & $3 \mathrm{H}$ & Methyl group \\
\hline $\mathrm{C} 20$ & 1.3151 & & \\
\hline $\mathrm{C} 21$ & 0.8976 & $3 \mathrm{H}$ & Methyl group \\
\hline $\mathrm{C} 22$ & 1.1876 & $1 \mathrm{H}$ & \\
\hline $\mathrm{C} 23$ & 1.19 & $1 \mathrm{H}$ & \\
\hline $\mathrm{C} 24$ & 1.10 & & \\
\hline $\mathrm{C} 25$ & 1.036 & & \\
\hline $\mathrm{C} 26$ & 1.55 & $3 \mathrm{H}$ & Methyl group \\
\hline $\mathrm{C} 27$ & 0.9912 & $3 \mathrm{H}$ & Methyl group \\
\hline $\mathrm{C} 28$ & 0.8283 & & \\
\hline C29 & 0.8349 & $3 \mathrm{H}$ & Methyl group \\
\hline
\end{tabular}

NMR: Nuclear magnetic resonance

\section{Isolation and purification of $\boldsymbol{\beta}$-sitosterol}

For isolation and purification of $\beta$-sitosterol, preparative TLC plate was conducted on $2 \mathrm{~g}$ of hexane extract corresponding to $100 \mathrm{~g}$ of the plant to give $47 \mathrm{mg}$ of $\beta$-sitosterol $(0.5 \%)$. The solvent system used was chloroform:acetone. The band of isolated compound was observed by the development of violet spots at plate side after spraying by vanillin sulfuric acid spray reagent.

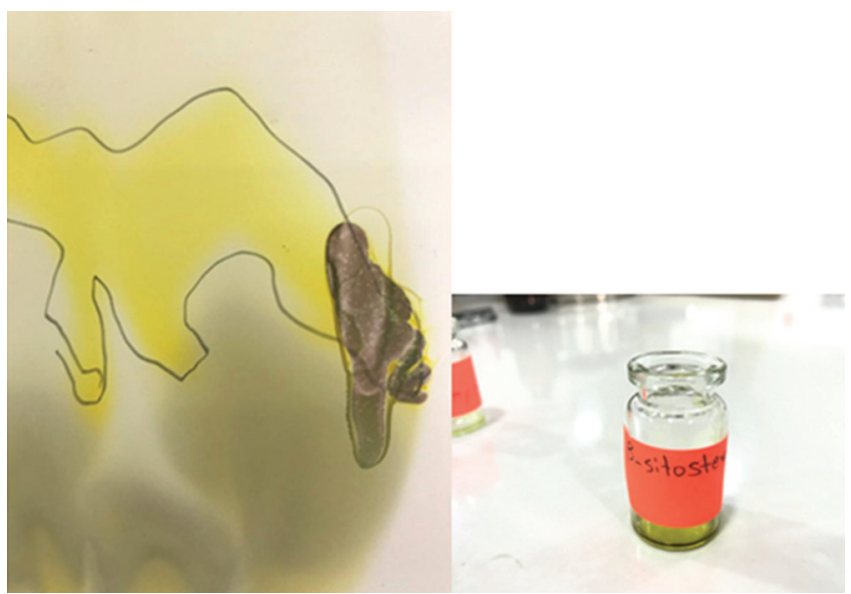

Structure elucidation of $\boldsymbol{\beta}$-sitosterol

\section{FT-IR spectrum}

The FT-IR spectra of the $\beta$-sitosterol (Fig. 6) showed the characteristic absorption bands by which its functional groups were identified.
The values of the characteristic bands of these spectra have been discussed according to the Lukitaningsih book [10], and summarized in Table 2.

\section{${ }^{1} H-N M R$}

The analysis was used to identify the target compound. The spectra were recorded in chloroform solvent. The values of chemical shifts have been discussed according to the Silverstein et al. [11] books and summarized in Table 3

\section{CONCLUSION}

E. angustifolia of Iraq contains significant amount of sitosterol, and further studies needed to investigate the presence of other sterol like stigmasterol which is reported to be found in the plant.

\section{ACKNOWLEDGMENT}

The author is deeply grateful to the College of Pharmacy/University of Al Mustansiriya for supporting this project and for giving us the opportunity and facilities to achieve this work.

\section{AUTHORS' CONTRIBUTIONS}

Rand A Zeez has provided the design, innovations, and isolation of $\beta$-sitosterol from $E$. angustifolia cultivated in Iraq. Ibrahim $S$ Abaashas majority performed the experiment in the laboratory. Enas J Kadhimhasaminor role in the conducting the experiment in the laboratory, analysis of obtaining data with characterisation of $\beta$-sitosterol from E. angustifolia.

\section{CONFLICTS OF INTEREST}

The author declare that there is no conflict of interest regarding the publication of this article.

\section{REFERENCES}

1. Sundaram S, Perumal PC, Gopalakrishnan VK. Chromatographic and spectrophotometric analysis of bioactive compounds from Cayratia trifolia (L.) stem. Int J Pharm Pharm Sci 2018;8:56-64.

2. Mohammed FI, Al-Essa MK, Shafagoj YA, Afifi FU. Investigation of the direct effects of the alcoholic extract of Elaeagnus angustifolia L. (Elaeagnaceae) on dispersed intestinal smooth muscle cells of guinea pig. Sci Pharm 2006;74:21-30

3. Katz GL, Shafroth PB. Biology, ecology and management of Elaeagnus angustifolia L.(Russian olive) in Western North America. Wetlands 2003;23:763-77.

4. Cansev A, Sahan Y, Celik G, Taskesen S, Ozbey H. Chemical properties and antioxidant capacity of Elaeagnus angustifolia L fruits. Asian J Chem 2011;23:2661-5

5. Farzaei MH, Bahramsoltani R, Abbasabadi Z, Rahimi R. A comprehensive review on phytochemical and pharmacological aspects of Elaeagnus angustifolia L. J Pharm Pharmacol 2015;67:1467-80.

6. Tehranizadeh ZA, Baratian A, Hosseinzadeh H. Russian olive (Elaeagnus angustifolia) as a herbal healer. BioImpacts: BI 2016;6:155-67.

7. Trautwein EA, Demonty I. Phytosterols: Natural compounds with established and emerging health benefits. Oléagineux Corps Gras Lipides 2007;14:259-66.

8. Ahmed OH, Hamad MN, Jaafar NS. Phytochemical investigation of Chenopodium murale (Family: Chenopodiaceae) cultivated in Iraq, isolation and identification of scopoletin and gallic acid. Asian J Pharm Clin Res 2017;10:70-7.

9. Wagner H, Bladt S. Plant Drug Analysis. $2^{\text {nd }}$ ed. Berlin: Springer; 1996.

10. Lukitaningsih E. Phytosterol content in bengkoang (Pachyrhizus erosus). Pharmacon: J Farmasi Indones 2012;13:47-54.

11. Silverstein RM, Webster XF, Kiemle DJ. Spectrometric Identification of Organic Compound. $7^{\text {th }}$ ed. New York: Wiley-Interscience; 2005. 